\title{
Atmospheric Pressure Photoionization Proton Transfer for Complex Organic Mixtures Investigated by Fourier Transform Ion Cyclotron Resonance Mass Spectrometry
}

\author{
Jeremiah M. Purcell, ${ }^{\mathrm{a}, \mathrm{b}}$ Christopher L. Hendrickson, ${ }^{\mathrm{a}, \mathrm{b}}$ \\ Ryan P. Rodgers, ${ }^{\mathrm{a}, \mathrm{b}}$ and Alan G. Marshall ${ }^{\mathrm{a}, \mathrm{b}}$ \\ a National High Magnetic Field Laboratory, Florida State University, Tallahassee, Florida, USA \\ ${ }^{\mathrm{b}}$ Department of Chemistry, Florida State University, Tallahassee, Florida, USA
}

To further clarify the role of dopant solvent in proton transfer in atmospheric pressure photoionization (APPI), we employ ultrahigh-resolution FT-ICR mass analysis to identify $\mathrm{M}^{+},[\mathrm{M}+\mathrm{H}]^{+},[\mathrm{M}-\mathrm{H}]^{-}$, and $[\mathrm{M}+\mathrm{D}]^{+}$species in toluene or perdeuterotoluene for an equimolar mixture of five pyrrolic and pyridinic nitrogen heterocyclic model compounds, as well as for a complex organic mixture (Canadian Athabasca bitumen middle distillate). In the petroleum sample, the protons in the $[\mathrm{M}+\mathrm{H}]^{+}$species originate primarily from other components of the mixture itself, rather than from the toluene dopant. In contrast to electrospray ionization, in which basic (e.g., pyridinic) species protonate to form $[\mathrm{M}+\mathrm{H}]^{+}$ positive ions and acidic (e.g., pyrrolic) species deprotonate to form $[\mathrm{M}-\mathrm{H}]^{-}$negative ions, APPI generates ions from both basic and acidic species in a single positive-ion mass spectrum. Ultrahigh-resolution mass analysis (in this work, $\mathrm{m} / \Delta \mathrm{m}_{50 \%}=500,000$, in which $\Delta \mathrm{m}_{50 \%}$ is the mass spectral peak full width at half-maximum peak height) is needed to distinguish various close mass doublets: ${ }^{13} \mathrm{C}$ versus ${ }^{12} \mathrm{CH}(4.5 \mathrm{mDa}),{ }^{13} \mathrm{CH}$ versus ${ }^{12} \mathrm{CD}(2.9 \mathrm{mDa})$, and $\mathrm{H}_{2}$ versus D (1.5 mDa). (J Am Soc Mass Spectrom 2007, 18, 1682-1689) (C) 2007 American Society for Mass Spectrometry

A tmospheric pressure photoionization (APPI) forms positive ions through several mechanisms that include proton transfer reactions $[1,2]$. As for electrospray ionization (ESI), a protic compound must be present in solution or the gas phase to facilitate efficient proton transfer. ESI solutions typically include an acid (positive ion) or base (negative ion) at $\sim 1 \%$ by volume. Likewise, APPI can have an additional protic solvent added to solution. For example, acetonitrile or methanol has been used successfully to increase protonation of neutral analytes $[3,4]$. Furthermore, toluene is often added as a dopant to increase ion yield by proton transfer and/or charge exchange reactions $[5,6]$. Specifically for protonation, a compound with a higher proton affinity than the benzyl radical will form the desired $[\mathrm{M}+\mathrm{H}]^{+}$ion $[1,3]$. Conversely, charge exchange reactions can produce $\mathrm{M}^{+}$if the ionization potential of the toluene cation is higher than that of the analyte.

Anions can also be formed in the APPI source. Acidic species can deprotonate to form $(\mathrm{M}-\mathrm{H})^{-}$and positive electron affinity compounds can capture thermal elec-

Address reprint requests to Dr. A. G. Marshall, Department of Chemistry, Florida State University, National High Magnetic Field Laboratory, 1800 E. Paul Dirac Drive, Tallahassee, FL 32310, USA. E-mail: marshall@magnet. fsu.edu trons and form $\mathrm{M}^{-\bullet}$. Kostiainen et al. studied negative ion formation mechanisms by investigating ionization efficiency and ion type (even- or odd-electron ion) for analytes of different polarity in various solvents [3, 7]. Traldi et al. reported negative ion formation by resonant electron capture from thermal electrons originating from metal surfaces and dopant [8].

Appropriately, these positive and negative ion formation mechanistic studies have involved various compounds mass analyzed sequentially. The molecular structure (i.e., polarity) of the selected compounds and solvent system govern the efficiency of positive and negative ion formation and the proton donor species could be theoretically and experimentally determined.

However, complex mixtures can contain many potential proton donors. Negative and positive ions can be formed simultaneously in the APPI source. Furthermore, negative-ion APPI Fourier transform ion cyclotron resonance (FT-ICR) mass spectrometry of a crude oil can produce $>12,000$ spectral peaks, more than $99 \%$ of which arise from deprotonated compounds (i.e., proton donors) [9]. In this work, we couple APPI with a 9.4 tesla FT-ICR mass spectrometer [10] for analysis of a petroleum sample to investigate proton transfer reactions with deuterated toluene, and thereby determine the extent of toluene's contribution to protonation (deu- 
teration) of analyte ions in a complex mixture. The complexity of the petroleum sample and the presence of close mass doublets (see below) require the highresolution and mass accuracy afforded by FT-ICR mass spectrometry [11] to resolve and assign molecular formulas to the various deuterated versus protonated compounds.

Relative to ESI, APPI has the advantage of access to much less polar analytes, such as thiophenes, furans, and polycyclic aromatic hydrocarbons. Another recently demonstrated advantage of APPI MS for nitrogen-class compounds is that APPI can differentiate between pyridinic versus pyrrolic nitrogen species in a single positive-ion mass spectrum, whereas electrospray ionization requires acquisition of both positive- and negative-ion mass spectra [12]. Here, we chose to analyze petroleum with high nitrogen content because those nitrogen compounds readily participate in proton transfer reactions (the subject of this paper).

\section{Experimental}

\section{Solvents and Compounds}

Model compounds and deuterated toluene $\left(C_{7} D_{8}\right)$ were purchased from Sigma-Aldrich (St. Louis, MO). The aromatic nitrogen compounds were prepared in equimolar concentration $(50 \mu \mathrm{M})$ in deuterated toluene.

\section{Crude Oil}

Three Athabasca Canadian bitumen distillates were provided by the National Center for Upgrading Technologies (NCUT), Devon, Alberta, Canada. The bitumen distillation cuts were diluted in toluene (500 $\mu \mathrm{g} / \mathrm{mL}$ ) or deuterated toluene and analyzed without further preparation. A Thermo Fisher Scientific (Lakewood, NJ) CHNS-O Flash EA elemental analyzer provided elemental weight percentages for the bitumen: carbon $84.1 \pm 0.06 \%$ RSD, hydrogen $11.1 \pm 0.01 \%$ RSD, nitrogen $0.236 .0 \%$ RSD, sulfur $3.4 \pm 1.1 \%$ RSD, oxygen $0.88 \pm 1.2 \%$ RSD.

\section{APPI Source}

The APPI source was supplied by Thermo Fisher Scientific. The vaporized analyte gas stream flows orthogonally to the mass spectrometer inlet (heated metal capillary) and the krypton vacuum UV lamp. The source was interfaced via a custom-built adapter to the first differentially-pumped stage of the 9.4 tesla FT-ICR mass spectrometer through a heated metal capillary [9]. A Harvard stainless steel syringe $(8 \mathrm{~mL})$ and syringe pump delivered solution to the heated nebulizer of the APPI source. In the APPI source, solvent flow rate was $50 \mu \mathrm{L} / \mathrm{min}$; the nebulizer heater was operated at 250 to $350{ }^{\circ} \mathrm{C}$ with carbon dioxide as the sheath gas at 50 p.s.i., and the auxiliary gas port was closed.

\subsection{Tesla FT-ICR MS}

All experiments were performed with a custom-built FT-ICR mass spectrometer equipped with a passively shielded Oxford 9.4 tesla superconducting magnet $[10,13]$. In the first octopole, ions are accumulated $(\sim 1$ s) [14] before transfer through a quadrupole (not operated in mass-resolving mode) into a second rf-only octopole where they are collisionally cooled (10-20 ms) with helium before transfer through an rf-only octopole to a $10 \mathrm{~cm}$ diameter, $30 \mathrm{~cm}$-long open cylindrical Penning ion trap. Multiple (50 to 200) time-domain acquisitions were summed for each sample, Hanningapodized $\left(\cos ^{2}(\pi \mathrm{t} / 2 \mathrm{~T})\right.$, in which $\mathrm{T}$ is time-domain data acquisition period), and zero-filled once before fast Fourier transform and magnitude calculation [15]. Measured ICR frequency was converted to mass-to-charge ratio $(\mathrm{m} / \mathrm{z})$ by the usual quadrupolar trapping potential approximation [16, 17]. Negative ion data were collected with similar parameters and appropriate polarity changes. All observed ions were singly-charged, based on the unit $m / z$ separation between ${ }^{12} C_{n}$ and ${ }^{13} C_{1}{ }^{12} C_{n-1}$ isotopic variants of the same elemental composition [18]. Therefore, mass spectral peak positions are reported in $\mathrm{Da}$ rather than as $m / z$.

\section{Results and Discussion}

Canadian bitumen tar sands have a relatively high nitrogen content. ESI FT-ICR mass spectrometry efficiently ionizes the acidic (pyrrolic) and basic (pyridinic) nitrogen classes in petroleum through proton transfer reactions [19-21]. Prior APPI analysis of a petroleum sample and nitrogen model compounds showed similar ionization trends (compared to ESI) for aromatic nitrogen compounds with additional radical molecular cation formation (primarily for other heteroatom class compounds). Aromatic nitrogen species preferentially form $(\mathrm{M}+\mathrm{H})^{+}$or $(\mathrm{M}-\mathrm{H})^{-}$in the APPI source and therefore provide a good test bed for investigation of proton transfer reactions in complex mixtures.

\section{Nitrogen Class Compounds}

Five aromatic nitrogen compounds (Figure 1) were chosen to model the proton transfer reaction. The structure of the nitrogen-containing ring determines the preferred ionization mechanism. For five-membered nitrogen rings, the hydrogen bonded to the nitrogen atom is acidic and preferentially deprotonates. On the other hand, the six-membered nitrogen ring species are basic (because of the electron lone pair on nitrogen) and efficiently protonate. Thus, two of the model compounds are basic, two are acidic, and the remaining compound (ellipticine) has both acidic and basic moieties.

The negative-ion APPI FT-ICR mass spectrum (Figure 2) of an equimolar solution of all five nitrogen compounds in deuterated toluene shows ions only for the acidic 
<smiles>c1ccc2nc3ccccc3cc2c1</smiles>

\section{Acridine \\ $\mathrm{C}_{13} \mathrm{H}_{9} \mathrm{~N} \quad$ MW: 179.073 DBE 10}

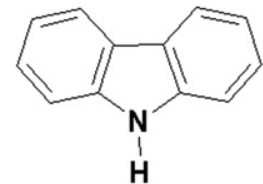

Carbazole

$\mathrm{C}_{12} \mathrm{H}_{9} \mathrm{~N} \quad$ MW: 167.073 DBE 9

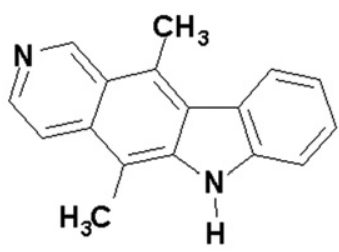

Ellipticine

$\mathrm{C}_{17} \mathrm{H}_{14} \mathrm{~N}_{2} \quad$ MW: 246.115

DBE 12<smiles>Cc1ccc2nc3c(ccc4ccccc43)c(C)c2c1</smiles>

7,9-dimethylbenz[c]acridine

$\mathrm{C}_{19} \mathrm{H}_{15} \mathrm{~N} \quad \mathrm{MW}: \mathbf{2 5 7 . 1 2 0}$

DBE 13

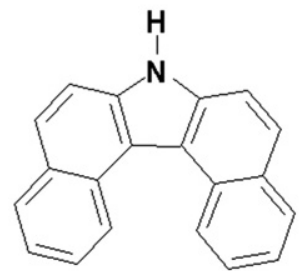

7H-dibenzo[c,g]carbazole

$\mathrm{C}_{20} \mathrm{H}_{13} \mathrm{~N}$ MW: 267.104

DBE 15

Figure 1. Five aromatic nitrogen compounds chosen to model petroleum acidic and/or basic compounds. Five-membered ring nitrogen structures are acidic and six-membered ring nitrogen species are basic.

species. No radical anions $\left(\mathrm{M}^{-}\right)$appear. Under continuous APPI source operation, the mass spectrometer was reconfigured for positive ion detection (Figure 3). All five nitrogen model compounds yield positive ions by APPI. The pyrrolic compounds (carbazole and 7H-dibenzo[c,g] carbazole) primarily form radical cations, $\mathrm{M}^{+} \bullet$ (Table 1), whereas the pyridinic compounds (acridine and 7,9dimethylbenz[c]acridine) protonate to form $[\mathrm{M}+\mathrm{H}]^{+}$. Ellipticine, which contains both a pyrrolic and a pyri- dinic moiety, preferentially forms $[\mathrm{M}+\mathrm{H}]^{+}$. Table 1 lists the ion relative abundances for each compound, and the parenthetical values are the percentages of $\mathrm{M}^{+},[\mathrm{M}+\mathrm{H}]^{+}$, and $[\mathrm{M}+\mathrm{D}]^{+}$for each compound. For the pyridinic species, the ratio of $[\mathrm{M}+\mathrm{D}]^{+}$to $[\mathrm{M}+\mathrm{H}]^{+}$ was 0.10 to 0.15 (see upper left inset in Figure 3). In contrast, there was no detectable $[\mathrm{M}+\mathrm{D}]^{+}$for the pyrrolic class compounds (which did form $[\mathrm{M}+\mathrm{H}]^{+}$in low abundance). Interestingly, $7 \mathrm{H}$-dibenzo[c,g]carba-

\section{Negative-Ion APPI 9.4 Tesla FT-ICR MS in $\mathrm{C}_{7} \mathrm{D}_{8}$}
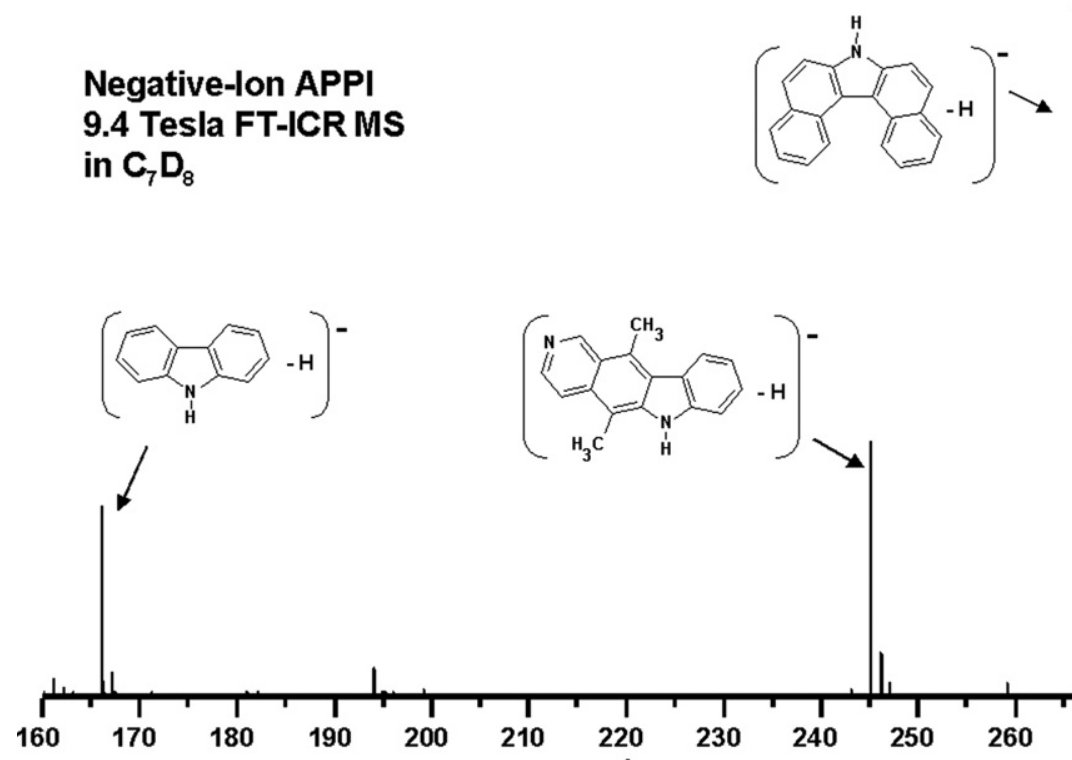

Figure 2. Negative-ion APPI FT-ICR mass spectrum of an equimolar solution of the model compounds of Figure 1 in deuterated toluene. Only the acidic compounds containing a pyrrole ring deprotonate to yield $[\mathrm{M}-\mathrm{H}]^{-}$ions, none of which contained deuterium. 


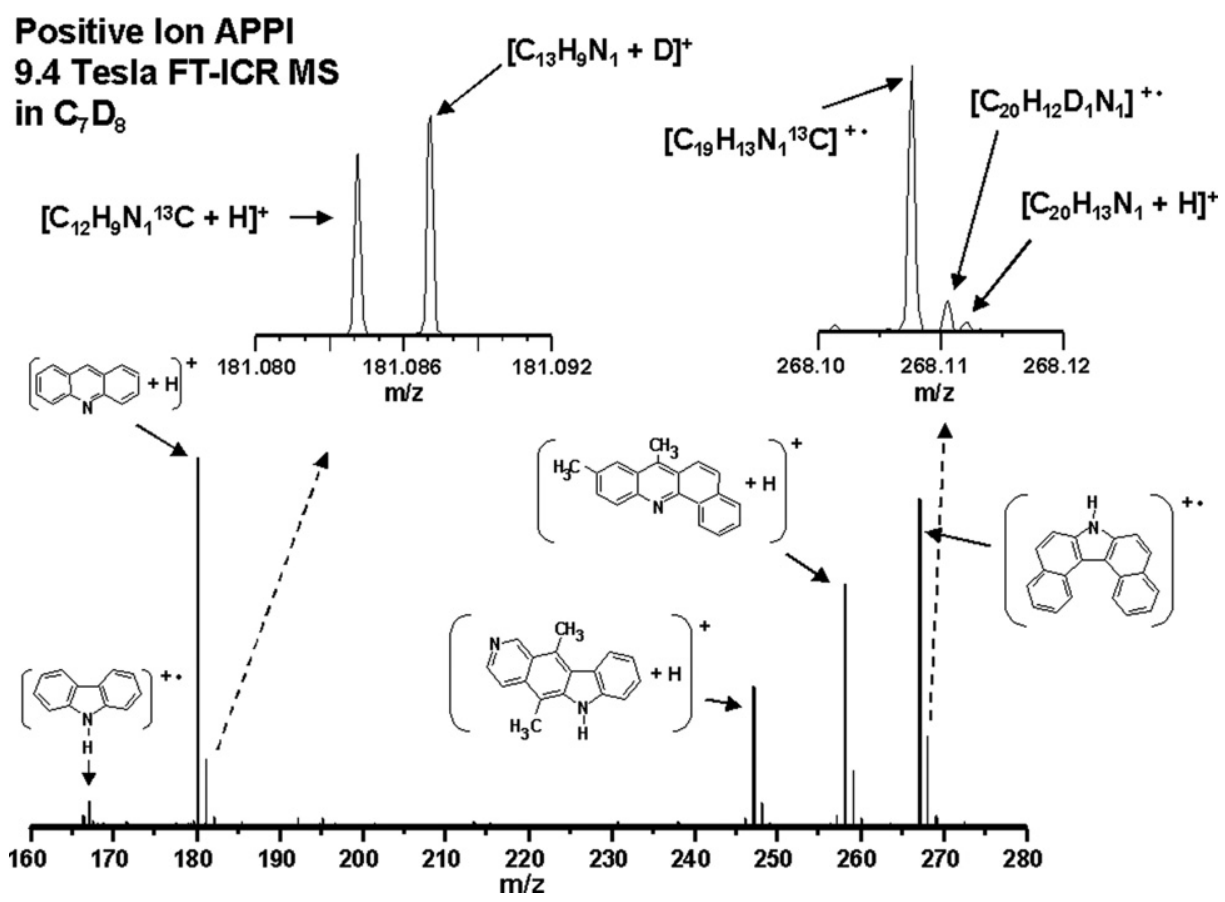

Figure 3. Positive-ion APPI FT-ICR mass spectrum of an equimolar solution of the model compounds of Figure 1 in deuterated toluene. All five compounds yielded positive molecular $\left(\mathrm{M}^{+} \bullet\right.$ ) or quasimolecular $\left([\mathrm{M}+\mathrm{H}]^{+}\right)$ions. The compounds containing a six-membered pyridinic ring are sufficiently basic to readily protonate (or deuterate) (along with $\sim 1 \%$ of radical molecular radical cations), whereas the more acidic compounds containing a five-membered pyrrolic ring form molecular radical cations, and $<1 \%$ protonation (or deuteration). For the even-electron species, the extent of deuteration was $\sim 15 \%$ for acridine (see the mass scale expanded inset spectrum), $\sim 10 \%$ for ellipticine, and $\sim 14 \%$ for 7,9-dimethylbenz[c]acridine. Also, at nominal mass 268 (right mass scale-expanded inset), 7H-dibenzo[c,g]carbazole exhibits slight hydrogen-deuterium exchange.

zole exhibited minor hydrogen-deuterium exchange $\left[\mathrm{C}_{20} \mathrm{H}_{12} \mathrm{D}_{1} \mathrm{~N}_{1}\right]^{+}$(see Figure 3 ). Carbazole also participates in hydrogen-deuterium exchange, but in low relative abundance.

\section{Bitumen Distillation Cuts}

Three Canadian bitumen petroleum distillation cuts were analyzed by positive-ion APPI FT-ICR MS. Mass analysis (with $\sim 100$ ppb mass accuracy) for all three cuts showed that $\sim 90 \%$ of the compounds contain at least one nitrogen atom. Furthermore, the $\mathrm{N}_{1}$ class ("class" denotes $\mathrm{N}_{\mathrm{n}} \mathrm{O}_{\mathrm{o}} \mathrm{S}_{\mathrm{s}}$ heteroatom composition) ions consist primarily of protonated compounds (>97\%). Figure 4 shows the heteroatom class distributions (both APPI and ESI) for the middle

Table 1. Positive-ion APPI FT-ICR MS ion relative abundances for the five aromatic nitrogen compounds of Figure 1

\begin{tabular}{lccc}
\hline \multicolumn{1}{c}{ Compound } & $\mathrm{M}^{+\bullet}$ & {$[\mathrm{M}+\mathrm{H}]^{+}$} & {$[\mathrm{M}+\mathrm{D}]^{+}$} \\
\hline \hline Carbazole & $2.7(87)$ & $0.4(13)$ & - \\
Acridine & $0.4(1)$ & $39.0(84)$ & $7.0(15)$ \\
Ellipticine & $0.8(5)$ & $14.8(85)$ & $1.8(10)$ \\
7,9-dimethylbenz[c]acridine & $1.2(3)$ & $25.6(83)$ & $4.2(14)$ \\
7H-dibenzo[c,g]carbazole & $34.6(99)$ & $0.4(1)$ & - \\
\hline
\end{tabular}

Parenthetical values show the percentages of $\mathrm{M}^{+} \bullet,[\mathrm{M}+\mathrm{H}]^{+}$, and $[M+D]^{+}$for each compound. distillation cut $\left(475-500{ }^{\circ} \mathrm{C}\right)$. Note the absence of the $S_{1}, S_{2}$, $\mathrm{HC}$, and $\mathrm{O}_{1} \mathrm{~S}_{1}$ classes in the ESI data. Further evidence for the different ionization patterns for APPI versus ESI is provided by the elemental relative abundances shown in Table 2. Positive- (negative-)ion ESI preferentially ionizes basic (acidic) species, whereas both polar and nonpolar species can be generated by positive-ion APPI.

Unlike electrospray ionization sources [22, 23], atmospheric pressure chemical ionization [24], or field desorption ionization [25], the APPI source produces both positive and negative ions simultaneously. Broadband APPI positive- and negative-ion mass spectra (not shown) were obtained for the middle distillation cut. Both spectra were collected without ion source interruption by reversing DC voltage polarity for ion transfer and trapping.

\section{Deuteration Versus Protonation}

The Canadian bitumen middle distillation cut was dissolved in deuterated toluene and mass analyzed. The deuterated toluene sample produced a class distribution (not shown) identical to that for the toluene sample (Figure 4). Due to the sample complexity ( 2000 molecular species within a $400 \mathrm{Da}$ mass window), the ultrahigh resolving power of FT-ICR mass spectrometry was essen- 
(+)APPI and ESI FT-ICR MS

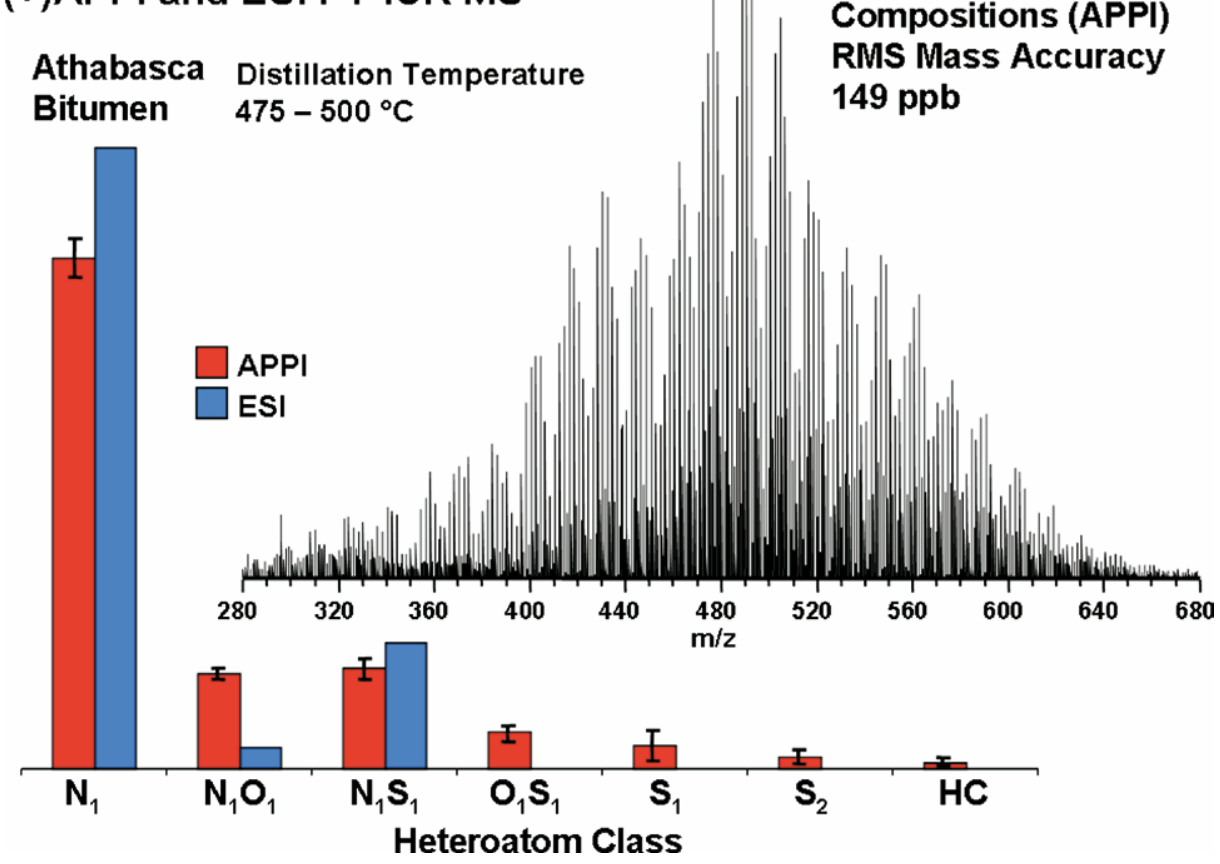

Figure 4. APPI positive-ion FT-ICR mass spectrum (upper right) and heteroatom class distribution (lower left, along with the corresponding class distribution from ESI FT-ICR MS) for a bitumen mid-range distillate. Each class represents the relative ion abundance of species that contain the stated heteroatom(s) in the assigned molecular formula. The error bars for the APPI data are standard deviation computed from three separate sample preparations and analysis.

tial to resolve and identify the deuterated species. Figure 5 is a mass scale expanded segment from the bitumen broadband positive-ion mass spectrum. The $2.9 \mathrm{mDa}$ mass difference between two compounds that differ elementally by ${ }^{13} \mathrm{CH}$ versus $\mathrm{CD}$ requires a minimum mass resolving power of $160,000\left(\mathrm{~m} / \Delta \mathrm{m}_{50 \%}\right.$, in which $\Delta \mathrm{m}_{50 \%}$ is the mass spectral peak full width at half-maximum peak height). Furthermore, the $1.5 \mathrm{mDa}$ mass difference between $\mathrm{H}_{2}$ and $\mathrm{D}$ requires a minimum mass resolving power of 300,000 . Additional mass doublets unique to APPI mass spectra arise by virtue of the presence of radical molecular cations and (de)protonated compounds: namely, $4.5 \mathrm{mDa}$ separation [9] for ${ }^{13} \mathrm{C}$ of $\mathrm{M}^{+}$versus ${ }^{12} \mathrm{CH}$ of $[\mathrm{M}+\mathrm{H}]^{+}$and $1.5 \mathrm{mDa}$ separation for $\mathrm{H}_{2}$ of $\mathrm{M}^{+} \cdot$ versus $\mathrm{D}$ of $\left[\mathrm{M}-\mathrm{H}_{2}+\mathrm{D}\right]^{+}$. All of the above mass doublets could be resolved by FT-ICR mass spectrometry at an average mass resolving power of 500,000 for the seven assigned spectral peaks in Figure 5.

It is thus possible to quantitate the relative abundances of deuterated $\left(\left[\mathrm{C}_{33} \mathrm{H}_{49} \mathrm{~N}_{1}+\mathrm{D}\right]^{+}\right)$versus proton-

Table 2. Elemental relative abundance for Canadian bitumen, calculated from ESI or APPI FT-ICR mass spectral peak magnitudes

\begin{tabular}{lcclll}
\hline & $\% \mathrm{C}$ & $\% \mathrm{H}$ & $\% \mathrm{~N}$ & $\% \mathrm{O}$ & $\% \mathrm{~S}$ \\
\hline \hline (+) ESI & 84 & 11 & 2.9 & 0.16 & 1.2 \\
(-) ESI & 79 & 11 & 0.0 & 7.2 & 2.0 \\
(+) APPI & 84 & 11 & 2.6 & 0.60 & 1.9 \\
(-) APPI & 81 & 11 & 0.37 & 5.7 & 1.5 \\
\hline
\end{tabular}

ated $\left(\left[\mathrm{C}_{33} \mathrm{H}_{49} \mathrm{~N}_{1}+\mathrm{H}\right]^{+}\right)$ions identified in Figure 5. For the spectral segment in Figure 5, as well as the mass spectrum as a whole, the detected deuterated ions contributed $\left([\mathrm{M}+\mathrm{D}]^{+} /[\mathrm{M}+\mathrm{H}]^{+}\right) \approx 5 \%$ for the even-electron $\mathrm{N}_{1}$ class compounds. For other less abundant protonated species, any deuterated species were below the detection limit.

\section{Negative and Positive Ion Class Distributions}

Unique elemental compositions were assigned to both negative and positive ion mass spectral peaks based solely on accurate mass measurement [26] combined with sorting of homologous alkylation series [27, 28] to yield 1844 negative-ion elemental compositions with an RMS mass error of 105 parts-per-billion, and 1801 positive-ion elemental compositions with an RMS mass error of 149 parts-per-billion. Figure 6 displays the heteroatom classes for positive- and negative-ion APPI FT-ICR mass spectra. The elemental compositions for each ion class can be further sorted by DBE doublebond equivalents, in which DBE is the number of rings plus double bonds calculated from eq 1 :

$$
\begin{aligned}
& \text { Double Bond Equivalents }\left(\mathrm{C}_{c} H_{h} N_{n} \mathrm{O}_{o} S_{s}\right) \\
& \quad=c-h / 2+n / 2+1
\end{aligned}
$$

Representative structures for the most abundant DBE components of the most abundant $\left(\mathrm{N}_{1}\right)$ class com- 


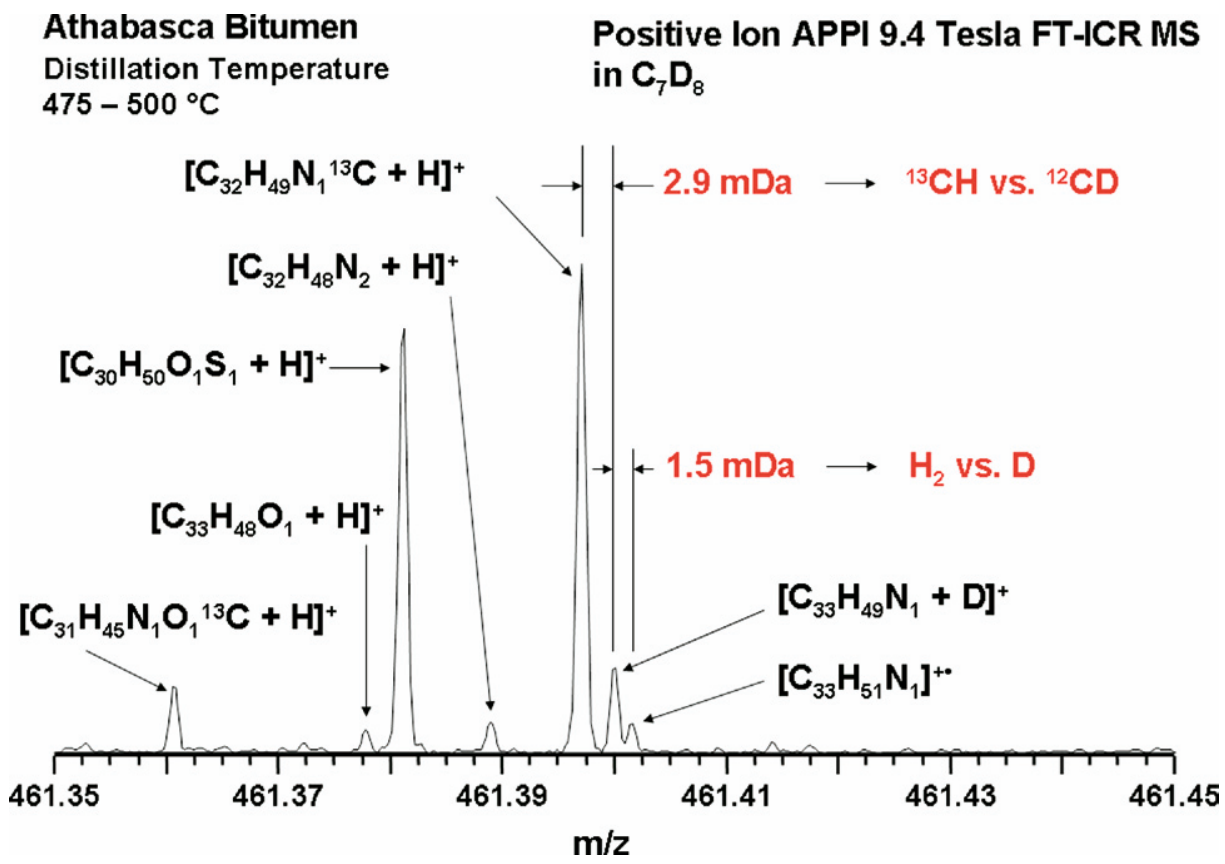

Figure 5. Positive-ion APPI FT-ICR mass scale-expanded segment of a bitumen mid-range distillate in deuterated toluene. This figure emphasizes the ultrahigh resolving power required to resolve the deuterated species in complex petroleum mixtures.

\section{Athabasca Bitumen Distillation Temperature $475-500^{\circ} \mathrm{C}$}

\section{APPI 9.4 Tesla FT-ICR MS}

DBE 9

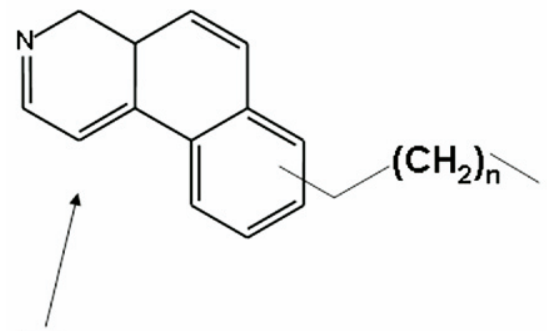

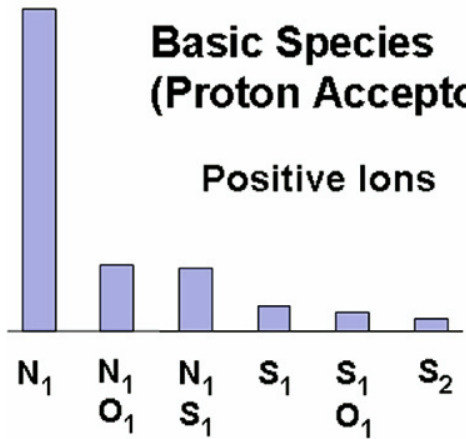

DBE 3

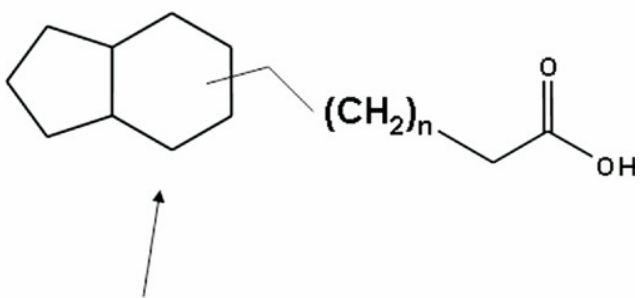

\section{Acid Species (Proton Donors)}

\section{Negative lons}

$$
\begin{array}{lllll}
\mathrm{O}_{2} & \mathrm{~S}_{1} & \mathrm{~N}_{1} & \mathrm{O}_{1} & \mathrm{O}_{3} \\
\mathrm{O}_{2} & & &
\end{array}
$$

Figure 6. Heteroatom class distribution for the positive and negative ions from a bitumen mid-range distillate. Generic structures are shown for the most abundant positive and negative species. DBE is the number of rings plus double bonds, and is calculated from eq 1 . Because only $\sim 5 \%$ of the even-electron $\mathrm{N}_{1}$ class ions contain deuterium, the acidic neutrals in the original sample are likely proton donors to form the even-electron species from basic neutrals. 
pounds are illustrated. Each molecular structure represents one of many possible isomers. Nevertheless, we can say that the nitrogen atom DBE $9 \mathrm{~N}_{1}$ class positive ion resides in a six-membered pyridinic ring.

\section{Need for Dopant}

We also performed APPI (data not shown) for a crude oil sample in methylene chloride (i.e., no charge-exchange dopant), and observed a dramatic shift (relative to toluene as solvent) in favor of protonated compounds relative to radical cations for both $\mathrm{N}_{1}$ and $\mathrm{C}_{\mathrm{c}} \mathrm{H}_{\mathrm{h}}$ classes. The sample was a processed petroleum that contained highly condensed polycyclic aromatic compounds $(20<\mathrm{DBE}<40)$, favoring charge-exchange (radical cation) reactions in the presence of toluene. However, APPI applications typically use a dopant to promote proton transfer, and toluene is a common dopant.

\section{Conclusions}

APPI of the nitrogen class compounds in a petroleum sample preferentially forms ions by means of proton transfer reactions. The Athabasca bitumen $\mathrm{N}_{1}$ class positive ions consist of $>97 \%$ protonated compounds and only $\sim 3 \%$ radical molecular cations. Based on their elemental compositions, all of the negative ions form by deprotonation of precursor neutrals. Aromatic nitrogen model compounds (Figures 2 and 3) exhibit similar ionization trends in which most of nitrogen species are ionized through proton transfer reactions (Table 1). Although pyrrolic species more efficiently form negative ions and pyridinic species positive ions, pyrrolic species can also form radical cations $\left(\mathrm{M}^{+}\right)$. Interestingly, the more aromatic pyrrolic compound (7H-dibenzo[c,g]carbazole) exhibited higher ion abundance (radical cation) than carbazole, suggesting that a more condensed aromatic core structure can add stability to a radical cation. The carbazole positive ion is present at low spectral magnitude (Figure 3). Carbazole is a likely proton donor to the pyridinic species and thus would be detected as a negative ion in higher abundance (as seen in Figure 2).

Negative and positive ions can be formed simultaneously in the APPI source and, therefore, there are many potential proton donors including toluene (or deuterated toluene) solvent. However, in the present bitumen sample, deuterated toluene donated a deuteron to only $10 \%$ to $15 \%$ of the even-electron ions formed from pyridinic nitrogen model compounds. Presumably, the proton donors for the pyridinic nitrogen compounds (for the model nitrogen compound spectra) are the pyrrolic (acidic) nitrogen compounds from the sample itself (even though the toluene dopant is present at orders of magnitude higher concentration).

For the petroleum sample, only $\sim 5 \%$ of the evenelectron nitrogen class species were deuterated. The most abundant negative-ion species is the $\mathrm{O}_{2}$ class, likely carboxylic acids. All species detected in the petroleum negative-ion spectrum were $[\mathrm{M}-\mathrm{H}]^{-}$. Reasonably, the even electron nitrogen class species that were protonated (not deuterated) are protonated through reactions with acidic species present in the sample.

\section{Acknowledgments}

This work was supported by NSF DMR 00-84,173, Florida State University, and the National High Magnetic Field Laboratory in Tallahassee, Florida. The authors thank the National Center for Upgrading Technologies, Devon, Alberta, Canada for providing the petroleum samples.

\section{References}

1. Robb, D. B.; Covey, T. R.; Bruins, A. P. Atmospheric Pressure Photoionization: An Ionization Method for Liquid Chromatography-Mass Spectrometry. Anal. Chem. 2000, 72, 3653-3659.

2. Tubaro, M.; Marotta, E.; Seraglia, R.; Traldi, P. Atmospheric Pressure Photoionization Mechanisms. 2. The Case of Benzene and Toluene Rapid Commun. Mass Spectrom. 2003, 17, 2423-2429.

3. Kauppila, T. J.; Kuuranne, T.; Meurer, E. C.; Eberlin, M. N.; Kotiaho, T.; Kostiainen, R. Atmospheric Pressure Photoionization Mass Spectrometry. Ionization Mechanism and the Effect of Solvent on the Ionization of Naphthalenes. Anal. Chem. 2002, 74, 5470-5479.

4. Marotta, E.; Seraglia, R.; Fabris, F.; Traldi, P. Atmospheric Pressure Photoionization Mechanisms. 1. The Case of Acetonitrile. Int. J. Mass Spectrom. 2003, 228, 841-849.

5. Hayen, H.; Karst, U. Strategies for the Liquid Chromatographic-Mass Spectrometric Analysis of Nonpolar Compounds. J. Chromatogr. A 2003 1000, 549-565.

6. Raffaelli, A.; Saba, A. Atmospheric Pressure Photoionization Mass Spectrometry. Mass Spectrom. Rev. 2003, 22, 318-331.

7. Kauppila, T. J.; Ostman, P.; Marttila, S.; Ketola, R. A.; Kotiaho, T.; Franssila, S.; Kostiainen, R. Atmospheric Pressure PhotoionizationMass Spectrometry with a Microchip Heated Nebulizer. Anal. Chem. 2004, 76, 6797-6801.

8. Basso, E.; Marotta, E.; Seraglia, R.; Tubaro, M.; Traldi, P. On the Formation of Negative Ions in Atmospheric Pressure Photoionization Conditions. J. Mass Spectrom. 2003, 38, 1113-1115.

9. Purcell, J. M.; Hendrickson, C. L.; Rodgers, R. P.; Marshall, A. G. Atmospheric Pressure Photoionization Fourier Transform Ion Cyclotron Resonance Mass Spectrometry for Complex Mixture Analysis. Anal. Chem. 2006, 78, 5906-5912.

10. Hakansson, K.; Chalmers, M. J.; Quinn, J. P.; McFarland, M. A Hendrickson, C. L.; Marshall, A. G. Combined Electron Capture and Infrared Multiphoton Dissociation for Multistage MS/MS in a Fourier Transform Ion Cyclotron Resonance Mass Spectrometer. Anal. Chem. 2003, 75, 3256-3262.

11. Marshall, A. G.; Hendrickson, C. L.; Jackson, G. S. Fourier Transform Ion Cyclotron Resonance Mass Spectrometry: A Primer. Mass Spectrom. Rev. 1998, 17, 1-35.

12. Purcell, J. M.; Rodgers, R. P.; Hendrickson, C. L.; Marshall, A. G. Speciation of Nitrogen Containing Aromatics by Atmospheric Pressure Photoionization or Electrospray Ionization Fourier Transform Ion Cyclotron Resonance Mass Spectrometry. J. Am. Soc. Mass Spectrom. 2007, 18, $000-000$.

13. Senko, M. W.; Hendrickson, C. L.; Pasa-Tolic, L.; Marto, J. A.; White, F. M.; Guan, S.; Marshall, A. G. Electrospray Ionization Fourier Transform Ion Cyclotron Resonance at 9.4 t. Rapid Commun. Mass Spectrom. 1996, 10, 1824-1828.

14. Senko, M. W.; Hendrickson, C. L.; Emmett, M. R.; Shi, S. D. H.; Marshall, A. G. External Accumulation of Ions for Enhanced Electrospray Ionization Fourier Transform Ion Cyclotron Resonance Mass Spectrometry. J. Am. Soc. Mass Spectrom. 1997, 8, 970-976.

15. Marshall, A. G.; Verdun, F. R. Fourier transforms in NMR, Optical, and Mass Spectrometry, A User's Handbook; Elsevier: Amsterdam, 1990, pp. $80-82,102-105$.

16. Ledford, E. B.; Jr.; Rempel, D. L.; Gross, M. L. Space Charge Effects in Fourier Transform Mass Spectrometry. Mass Calibration. Anal. Chem. 1984, 56, 2744-2748.

17. Shi, S. D.-H.; Drader, J. J.; Freitas, M. A.; Hendrickson, C. L.; Marshall, A. G. Comparison and Interconversion of the Two Most Common Frequency-to-Mass Calibration Functions for Fourier Transform Ion Cyclotron Resonance Mass Spectrometry. Int. J. Mass Spectrom. 2000, 195/196, 591-598.

18. Senko, M. W.; Beu, S. C.; McLafferty, F. W. Automated Assignment of Charge States from Resolved Isotopic Peaks for Multiply Charged Ions. J. Am. Soc. Mass Spectrom. 1995, 6, 52-56. 
19. Rodgers, R.; Schaub, T.; Marshall, A. Petroleomics: MS Returns to Its Roots. Anal. Chem. 2005, 77, 20A-27A.

20. Qian, K.; Robbins, W. K.; Hughey, C. A.; Cooper, H. J.; Rodgers, R. P.; Marshall, A. G. Resolution and Identification of Elemental Compositions for More than 3000 Crude Acids in Heavy Petroleum by Negative-Ion Microelectrospray High Field Fourier Transform Ion Cyclotron Resonance Mass Spectrometry. Energy Fuels 2001, 15, 1505-1511.

21. Rodgers, R. P.; Hendrickson, C. L.; Emmett, M. R.; Marshall, A. G. Reading Chemical Fine Print: Resolution and Identification of 3000 Nitrogen-Containing Aromatic Compounds from a Single Electrospray Ionization Fourier Transform Ion Cyclotron Resonance Mass Spectrum of Heavy Petroleum Crude Oil. Energy Fuels 2001, 15, Spectrum

22. Emmett, M. R.; Caprioli, R. M. Microelectrospray Mass Spectrometry: Ultra-High-Sensitivity Analysis of Peptides and Proteins. J. Am. Soc. Mass Spectrom. 1994, 5, 605-613.

23. Fenn, J. B.; Mann, M.; Meng, C. K.; Wong, S. F.; Whitehouse, C. M Electrospray Ionization for Mass-Spectrometry of Large Biomolecules. Science 1989, 246, 64-71.
24. Carroll, D. I.; Dzidid, I.; Stillwell, R. N.; Haegele, K. D.; Horning, E. C. Atmospheric-Pressure Ionization Mass-Spectrometry-Corona Discharge Ion-Source for Use in Liquid Chromatograph Mass Spectrometer Computer Analytical System. Anal. Chem. 1975, 47, 2369-2373.

25. Schaub, T. M. Hendrickson, C. L.; Qian, K.: Quinn, J. P.; Marshall, A. G. High-Resolution Field Desorption Ionization Fourier Transform Ion Cyclotron Resonance High-Resolution Mass Analysis of Nonpolar Molecules. Anal. Chem. 2003, 75, 2172-2176.

26. Kim, S. Rodgers, R. P. Marshall, A. G. Truly "Exact” Mass: Elemental Composition Can Be Determined Uniquely from Molecular Mass Measurement at $\sim 0.1 \mathrm{mDa}$ accuracy for molecules up to $\sim 500 \mathrm{da}$. Int. J. Mass Spectrom. 2006, 251, 260-265.

27. Hughey, C. A.; Hendrickson, C. L.; Rodgers, R. P.; Marshall, A. G.; Qian, K. Kendrick mass defect spectrum: A compact visual analysis for ultrahigh-resolution broadband mass spectra. Anal. Chem. 2001, 73, $4676-4681$.

28. Kendrick, E. Mass Scale Based on $\mathrm{CH}_{2}=14.0000$ for High-Resolution Mass Spectrometry of Organic Compounds. Anal. Chem. 1963, 35, $2146-2154$ 